\title{
A eficácia da capacidade contributiva e a justiça social ${ }^{1}$
}

\author{
The ability contribution efficacy and social justice
}

Carla Bonomo $^{2}$

\section{Resumo}

Verifica o presente estudo a eficácia jurídica e social do princípio da capacidade contributiva e sua aplicação aos tributos em geral a partir de uma análise críticodescritiva, por meio de pesquisa doutrinária. Uma noção da evolução histórica, bem como dos respectivos contextos social e econômico, de cada fase da humanidade, até a era contemporânea, demonstra que o Direito, de um modo geral, sempre teve em seu processo evolutivo, a observância de valores morais e éticos, que fundamentam e sustentam o núcleo básico dos princípios jurídicos. Aborda-se, ainda, a justiça social e fiscal e sua ligação com o princípio da capacidade contributiva, utilizando-se do marco teórico visto em John Rawls e Hans Kelsen. Observa-se, também, a doutrina italiana no tocante ao princípio em tela e as teorias subjetivas que analisam os aspectos pessoais norteadores do fenômeno da imposição fiscal. Analisa-se outros princípios fundamentais e as imunidades, remissões e, especialmente, as isenções fiscais, com ênfase no "mínimo isento", como institutos limitadores ao poder de tributar, a fim de verificar seus reflexos na eficácia jurídica e social do princípio. Tais estudos visam, ainda, averiguar a questão dos princípios constitucionais como normas e valores, sobretudo o princípio da capacidade contributiva e suas devidas aplicações aos impostos, taxas e contribuições de melhoria. Finalmente, expõe-se a eficácia social da capacidade contributiva.

Palavras Chave: Justiça social e fiscal; Princípios constitucionais tributários; Capacidade contributiva; Exonerações fiscais; Tributos.

\begin{abstract}
Check the study actual to juridical efficacy and social of the ability contribution beginning and his applying to duties in commom part in beginning of the analysis critical-descriptive, across the doctrine research. $\mathrm{Na}$ idea of historic evolution, as well as the respective context social and economical, each humanity aspect, until contemporaneous era, show that Law, at the most, always had in your evolutionary process, the morals and ethicals values remark, had established and support the basic nucleaus of the jurical beginning. Boarding, still, the social and fiscal justice and his linked with contribution ability beginning, using the theoric mark had notice

\footnotetext{
${ }^{1}$ Conclusão da Tese de Doutoramento em Direito Tributário; tendo realizado parte da dissertação de Mestrado em Gênova/Itália, junto ao escritório do Prof. Dr. Victor Uckmar

2 Professora Universitária, graduada em Direito pela Universidade Estadual de Londrina, Mestre em Direito Tributário pela PUC/SP, Doutora em Direito Tributário pela PUC/SP; professora orientadora nos cursos de pós-graduação e autora da obra "Direito Tributário" sob coordenação de José Cretella Neto. v. VII, coleção Compacta, ed. Forense, 1997.
}

Revista de Direito Púbuco, LondRINA, V, 4, N. 2, P. 29-42, M AIO/AGO. 2009 
in John Rawls and Hans Kelsen. Point out, also, the italian douctrine to economical ability beginning, and subjectives theories that checking personals aspects leadind the fiscal impositiam extraordinay. Find out others essentials beginning and imunities, remissions and, specially the fiscal abnegations, emphazising "minimum abnegation", like restrictions institutes to tribute power, with the purpose to check his thought in the judical and social efficacy of the contribution ability rule. Such researches point, to inquire the beginning constitucionals questions like norms and values, overcoat the ability contribution rule and his appliyng to tax, rate and perfect contribution. Finally, find the contribution ability social efficacy.

Keywords: Social and fiscal justice; Constitutionals tributaries principles; Contribution ability; Fiscal exonerations; Duties.

\section{Introdução}

A desigualdade social é fato que preocupa o homem desde as primeiras civilizações até os dias de hoje. Com o surgimento da 'propriedade', surgiu o homem civil e, com ele, a competição e 0 aumento das desigualdades sociais e, nesse contexto, outras características humanas passaram a aflorar, como a ambição e a inveja, criando empecilhos para a realização de uma sociedade justa.

A sociedade civil, em sua trajetória, evoluiu intelectual e culturalmente, informatizou-se e ampliou o leque de opções em todos os aspectos; no entanto, não para todos os cidadãos, pois uma grande fatia da população vive despojada e impossibilitada de interagir e de integrar de igual para igual a sociedade.

Eis que, assim, surgem as desigualdades sociais. Tais questões vinculam-se às políticas econômica e social e, a partir daí, tornam-se questões jurídicas. Este fato desvirtua o Estado de seu fim maior, que é oferecer uma estrutura social capaz de promover o bemestar comum, regulada por uma concepção comum de justiça.

A justiça como equidade se aplica à estrutura básica da sociedade e, como tal, é indissociável das justiças social e política, devendo ser aplicada, também, à justiça social.

\section{Justiça fiscal}

Trata-se, a justiça fiscal, de uma dimensão da justiça política, e é a que oferece melhor mecanismo de justiça distributiva. Justiça fiscal que, no processo evolutivo do direito tributário, teve lugar de destaque, trazendo a importante percepção de que os valores atribuídos para o pagamento dos tributos deveriam ajustar-s à capacidade econômica de 
cada indivíduo, ou melhor, que exista uma redistribuição de rendas.

Essa importante e eficaz redistribuição de rendas consiste na existência de um sistema jurídico-tributário que objetive evitar a concentração de rendas em mãos minoritárias. É necessária uma integração das justiças social, política e fiscal. Tais políticas se concretizam por meio do fisco, já que estão vinculadas às intervenções das instituições políticas e às previsões constitucionais.

0 tributo acompanha 0 ser humano desde as organizações mais primitivas, sofrendo mutações após a instauração do "Estado de Direito". No período do Estado Patrimonial, o tributo funcionava como pacto entre os detentores do poder e a população, passando a tributar compulsoriamente o patrimônio. 0 perío do do Estado Fiscal foi marcado por grandes evoluções, entre as quais, as voltadas para a liberdade humana e às iniciativas individuais e, com isso, o tributo passou a necessitar de limitações, a fim de que fossem mantidas as liberdades individuais e a propriedade privada. Surge, então, o mecanismo da capacidade contributiva de cada um, de acordo com suas posses.

A capacidade contributiva começa a ter conotação de princípio fundamental em matéria tributaria, sobretudo na sua organização social, onde o tributo passa a ser visto como dever de cidadania.

O dever de contribuir com as despesas públicas, atrelado ao princípio da capacidade contributiva, acarreta questionamentos do que é e o que pode ser valor justo a contribuir, ou seja, a justiça social e fiscal vista na sua relação com a justa distribuição de riquezas.

\section{Princípio como normas e como valores}

No estudo dos princípios jurídicos informadores do direito tributário, há duas vertentes que balizam os princípios constitucionais: princípios como normas e princípios como valores.

Princípios como normas, porquanto constituem-se em diretrizes do sistema jurídico, as quais 'iluminam' as demais normas jurídicas, apontando-lhe a verdadeira direção e sentido.

Já, princípios enquanto valores expressam uma idéia de valor e de direito. Ocupamse de conteúdos de maior imperatividade e são hierarquicamente superiores aos contidos nas demais normas jurídicas. A idéia de valor contida nos princípios volta-se aos valores 
morais da época e do local a serem aplicados, em especial para os direitos humanos; são mutáveis e adaptáveis. Os valores, por sua natureza, revestem-se de subjetividade e relatividade, devendo haver cuidadosa análise por parte do legislador e aplicador do direito.

Os princípios, de modo geral, são indissociáveis da justiça, da equidade e da moralidade, entre outros, sendo este o caminho a ser trilhado pelas normas jurídicas.

Princípios constitucionais são vetores de justiça social. Vejamos alguns deles: 0 princípio da legalidade, insculpido no inciso II, do artigo 5o da Constituição Federal, é de fundamental importância na criação e manutenção do Estado Democrático de Direito. 0 artigo 150, I do Texto Magno, exige que todos os elementos da obrigação tributária estejam disciplinados em lei. Sua ligação com o princípio da capacidade contributiva (art. 145, parágrafo 1ํㅡ, da Constituição Federal) não pode deixar de ser observada, de forma que 0 legislador ordinário, ao criar tributo, definir o fato gerador e fixar a alíquota, deve atender à idéia de que a tributação deve ser proporcional à manifestação de riqueza do contribuinte, bem como atentar às demais normas e princípios constitucionais, com ênfase no primado da igualdade, princípio base do regime democrático e que constitui o fundamento de todo 0 ordenamento jurídico.

Neste tocante, cumpre salientar que o princípio da capacidade contributiva consagra apenas uma igualdade relativa, garantindo tratamento igual a pessoas que se encontrem em situações equivalentes.

Em campo tributário, consiste em conferir condições equivalentes de capacidade econômica, garantindo que todos contribuam nas mesmas medidas e em razão de suas posses. Afasta-se, assim, hipóteses de concessão de vantagens tributárias em favor de grupos ou pessoas, de forma que o sacrifício econômico suportado pelo cidadão seja equivalente para todos que se encontram nas mesmas condições.

0 direito evoluiu e, com ele, os textos normativos tornaram-se mais eficazes na busca da satisfação dos anseios sociais, em especial, no que pertine à garantia dos direitos fundamentais.

Os princípios jurídico-constitucionais tributários Republicano, Segurança Jurídica, Vedação ao confisco, Proporcionalidade, Progressividade, Pessoalidade e Moralidade, Irretroatividade, Igualdade, Capacidade Contributiva, Legalidade, para funcionarem realmente como vetores de justiça social, devem ser aplicados conjuntamente, a fim de, 
efetivamente, orientar, iluminar as demais normas jurídicas tributárias, expressando uma idéia de valor e de direito, rumo à promoção de justiça social.

Para que haja tributação justa e eficácia plena do princípio da capacidade contributiva, basta que se dê cumprimento, de forma séria e cabal, aos princípios constitucionais tributários, já que estes pretendem proteger bens considerados de maior valor, no caso, os atrelados à dignidade humana, atentando-se sempre ao 'mínimo existencial'.

\section{Capacidade contritutiva}

Caso a obediência aos princípios constitucionais não ocorrer quando da criação de tributos, deverá ocorrer através de processo jurisdicional, que existe para a preservação de direitos do cidadão, assegurando que os efeitos pretendidos pelas normas efetivamente se propaguem no mundo dos fatos. Salienta-se que eficácia é o que pode ser exigido também judicialmente, quando necessário e em conformidade com as normas jurídicas.

Outros institutos jurídicos tributários, que situam-se nas dobras do principio da capacidade contributiva, devem ser observados e utilizados pelo poder público para a realização da justiça social e fiscal, como imunidades, isenções e remissões, como formas de exoneração do crédito tributário.

As imunidades restam dispostas no texto constitucional como regras de exceção, impedindo o pagamento de impostos sobre determinados fatos ou pessoas, carentes de capacidade econômica.

As remissões (art.156, VI e art. 172,I do Código Tributário Nacional), devem ser aplicadas a casos concretos, exonerando total ou parcialmente o crédito tributário. Enquanto o parágrafo primeiro do artigo 145 da Constituição dispõe que o princípio da capacidade contributiva aplica-se apenas à espécie tributária 'impostos', 0 art. 172, I do CTN impõe sua aplicabilidade a todos os tributos, eis que determina que a remissão aplica-se aos créditos tributários.

As isenções também realizam os ideais da capacidade contributiva, porquanto representam um 'favor legal' concedido a pessoas físicas ou jurídicas, de forma onerosa ou gratuita, exonerando-os de tributação. Aplicam-se mecanismos que estabelecem relação entre rendas e despesas, de forma a dar tratamento diferenciado àqueles que possuem 
rendas semelhantes, mas possuem despesas diferentes, a fim da atingir a justiça social e fiscal.

A capacidade contributiva impõe que os tributos sejam pagos na proporção dos recursos do contribuinte. 0 conceito de capacidade contributiva foi enaltecido e reforçado por vários estudiosos. No decorrer da história, Santo Tomás de Aquino e Adam Smith já desenvolviam seu conceito e sustentavam que os tributos devem ser pagos na proporção dos recursos do cidadão. Passados tantos séculos, o conteúdo e conceito de capacidade contributiva ainda é fervorosamente debatido e estudado e, nem sempre os resultados são satisfatórios.

Realizando-se um estudo de direito comparado no que toca a este assunto, sublinha-se que, na Itália, o princípio em tela constava já nas constituições italianas dos Estados pré-unitários. 0 Estatuto Albertino do Reino da Itália, datado de 4 de março de 1848, em seu art. 25, disciplinava o princípio da capacidade contributiva, enunciando que "os cidadãos contribuem indistintamente na proporção de seus haveres".

Posteriormente, na Alemanha, a Constituição da República de Weimar, no artigo 134, disciplinou, pela segunda vez e de forma expressa, o princípio da capacidade econômica.

Mais tarde, 0 artigo 53 da Constituição da República Italiana de 1948, substituiu 0 disposto no artigo 25 do Estatuto Albertino, dando ao princípio uma projeção mais abrangente.

Os textos constitucionais italianos supracitados possuem dessemelhanças, e as principais diferenças são aqui destacadas como: - 0 art. 53 da Constituição Italiana refere-se a "todos" indistintamente, enquanto o Estatuto Albertino referia-se aos "cidadãos"; - 0 art. 53 do texto republicano da Itália refere-se expressamente à capacidade contributiva, em quanto o Estatuto Albertino referia-se a "haveres"; o Estatuto Albertino prescrevia sobre os "encargos do Estado", enquanto a Consituição republicana refere-se às "despesas públicas" e, por fim: a Constituição Italiana utiliza o critério da progressividade, enquanto o Estatuto Albertino estatuía o critério da proporcionalidade.

O conceito de capacidade contributiva sempre gerou controvérsias na doutrina e jurisprudência italianas. 0 ordenamento jurídico italiano trouxe importante contribuição para a evolução do postulado da capacidade contributiva, especialmente por meio das 
teorias subjetivas que analisam os aspectos pessoais que norteiam o fenômeno da imposição tributária.

\section{A "causa impositions"}

A teoria da "causa impositions" afirma que a capacidade contributiva do sujeito é determinada pelos critérios da "vantagem" e do "benefício", os quais estabelcem limites para a participação do contribuinte nos encargos públicos.

Mais tarde, grande parte da doutrina italiana passou a sustentar que o preceito da capacidade econômica constituía uma "empty box" (caixa vazia), ou melhor, uma diretriz constitucional ou uma declaração programática destituída de eficácia jurídica vinculante.

A norma contida no art. 53 do diploma republicano italiano, veda a instituição de tributos que não sejam fundamentados na capacidade econômica de cada indivíduo da coletividade. No texto italiano, os princípios que mais irradiam efeitos sobre o principio da capacidade contributiva, além do fundamental principio de solidariedade econômica e social, contido no art. $2^{2}$, são os princípios da igualdade, efetividade, da isenção do mínimo vital, progressividade, generalidade e legalidade.

\section{Evolução do princípio no Brasil}

No Brasil, a capacidade contributiva integrou a Constituição Imperial, mas, num retrocesso, deixou de constar nas constituições seguintes, as de 1891, de 1934 e 1937, voltando em cena na constituição democrática de 1946. Neste texto, estendia-se a eficácia do principio a todos os tributos, tendo sido modificado pela emenda constitucional $n^{\underline{a}}$ 18/1965. Posteriormente, foi banida sua aplicabilidade nos textos constitucionais de 1967 e emenda constitucional $n^{\mathrm{a}}$ 1/1969.

Do que afirmou-se acima, pode-se depreender que a aplicabilidade do principio em questão, embora seja importante instrumento para a obtenção de justiça social e fiscal, capaz de oportunizar a isonomia entre os cidadãos, vem sendo depreciado pelos detentores do poder que, com isso, evidenciam seu desprezo para com o que deveria ser seu principal objetivo: a promoção do bem-estar e justiça sociais.

A falta de vontade política e a rendição dos governantes, em sua maioria, aos 
interesses de uma minoria detentora de grande poder aquisitivo, aliada a fortes sentimentos de egoísmo e ambição, levam nossos governantes à elaboração de leis que afrontam princípios jurídicos basilares e pétreos, legislando para o bem-estar de pequenos grupos.

\section{Justiça, igualdade e legalidade tributária}

Para a obtenção do bem-estar social em geral, é fundamental que os legisladores e aplicadores do direito, voltem sua atenção para os problemas que assolam a maior parte da população, que são vários, dentre os quais: desemprego, desigualdade de oportunidades e excessiva carga tributária. Esta última pesa sobre os ombros dos contribuintes que, como é sabido, é o pivô dos demais problemas sociais. 0 desrespeito à capacidade contributiva e sua aplicabilidade apenas a alguns tipos de impostos, cria desfalques nas finanças do empresário, acarretando o desemprego que, por sua vez, causa redução da capacidade econômica dos cidadãos que, desempregados e sem oportunidades continuam sendo alvos do fisco, que os endivida, agravando o caos social.

Conceituar capacidade contributiva implica adentrar em outros conceitos, como o de justiça, igualdade e legalidade tributária, pois estão interligados de forma compulsória.

A melhor definição de justiça é a de que esta é a intenção constante de dar a cada um o que é seu; e essa intenção apenas se concretizará com a aplicação de tratamento isonômico a todos, pois quanto menos desigualdades houver, mais justa será a vida social.

A igualdade tributária liga-se diretamente à capacidade contributiva, instrumento vigoroso no processo da busca por justiça fiscal. Em busca desta justiça, no âmbito da tributação, o procedimento consiste em dar a cada um o que é seu, como que num "daí a César o que é de César".

A capacidade contributiva é a riqueza disponível depois de satisfeitas as necessidade elementares da existência, riqueza que pode ser absorvida pelo Estado, sem reduzir o padrão de vida e as atividades econômicas do cidadão. É o denominado mínimo vital ou existencial.

É tarefa dos órgãos fazendários respeitarem este mínimo existencial e, através de meios objetivos, apurarem as necessidades básicas dos contribuintes. Tais meios devem ser voltados a dados sociais que efetivamente retratem a situação pessoal e familiar dos cidadãos. A apuração do mínimo vital, no entanto, não deve ser considerado o direito 
subjetivo do contribuinte, a ser oposto de forma incondicional ao Estado, mas sim em razão de critérios, mecanismos de aferição da real capacidade econômica.

Tanto no ordenamento jurídico constitucional brasileiro, como no italiano, a capacidade econômica manifesta-se por meio de índices ou expressões de riqueza, como renda, patrimônio, consumo, entre outros.

A doutrina italiana distingue tais manifestações em índices diretos e indiretos de capacidade contributiva. Índices diretos são aquelas expressões imediatas de riqueza dos indivíduos, como a renda e o patrimônio; os indiretos são todos os outros que manifestam capacidade contributiva em via mediata ou sintomática, como o consumo.

O principio em exame é norma jurídica de natureza constitucional, dado que se afere pela natureza dos interesses que tutela, possuindo conexão com os demais princípios constitucionais tributários, porquanto um principio não existe isolado, eles são estreitamente ligados entre si.

\section{Eficácia da norma}

Eficácia é aquilo que dá bom resultado, que produz o efeito pretendido. Norma eficaz é aquela revestida de força suficiente para produzir seus efeitos. A doutrina classifica a eficácia da norma e preceitua, de modo geral, que se os princípios constitucionais possuem diferentes e variados níveis eficacionais, estes níveis merecem uma classificação.

O principio da capacidade econômica possui, quase sempre, eficácia relativa complementável. Isso implica afirmar que referida norma não recebeu do legislador normatividade suficiente para sua aplicação imediata, passando a incidir sobre os interesses protegidos, somente após a emissão de complementação futura infraconstitucional, ou seja, dependente de complementação legislativa ampliativa de seus efeitos.

Tratar da questão eficacional da norma jurídica, leva a abordar as espécies de lacuna existentes em nosso ordenamento: ontológica, axiológica e técnica.

Lacuna ontológica dá-se quando a norma vigente deixa de corresponder à realidade fático-social; a axiológica observa-se quando a norma, sendo aplicada, acarreta situação injusta, por contrariar valores ideológicos de um povo; lacuna técnica ocorre sempre que houver ausência de normas infaconstitucionais a regulamentar, de forma especifica, determinado caso.

ReVIsta de DiReITo PúBlico, LondRINA, V, 4, N. 2, P. 29-42, M AIO/AGO. 2009. 
A norma jurídica referente ao principio da capacidade contributiva, por ser, em alguns casos, norma de eficácia relativa complementável, deixa de atingir diretamente eficácia jurídica e social face a ocorrência de lacuna técnica, mas alcança-a de forma indireta.

Este problema, observável neste tipo de lacuna, pode ser superado com a utilização, pelo juiz ou tribunal, da integração normativa ou pelo emprego da analogia, pois a norma, de uma forma ou de outra, deve atingir sua eficácia, não importando em qual grau de variação. Resta que os aplicadores do Direito tenham sempre em mente 0 fato de que 0 Direito nunca será imutável, assim como a humanidade. A sociedade. Suas idéias e valores se modificam, e o Direito deve se adaptar aos fatos reais, em dado local e momento, em busca de seu fim maior, que é a promoção do bem-estar comum.

Em alguns casos, como no imposto sobre a renda e imposto sobre propriedade de veículos automotores, em que a norma que contempla o principio da capacidade contributiva é dotada de eficácia plena, bastando por si só, por possuir possibilidade de produzir efeitos jurídicos concretos.

As taxas previstas constitucionalmente têm eficácia plena, como no caso de certidões de óbito e nascimento, bem como no caso das custas judiciais para pessoas pobres. Outras há que podem possuir eficácia relativa complementável, dependendo do caso.

A contribuição de melhoria é tributo decorrente de valorização imobiliária provocada por obra pública, cujas despesas são rateadas e arrecadadas dos proprietários dos imóveis beneficiados. Há uma omissão na lei, que não define se o valor a ser rateado e cobrado decorrerá das despesas com a obra ou da valorização do imóvel face a edificação da obra pública, assunto exaustivamente debatido pela doutrina.

Considerar como hipótese de incidência do tributo a valorização da obra contraria o ideal de justiça almejado, contrariando, também, valores morais, éticos e legais, acarretando enriquecimento ilícito em favor do Estado, que não tem como prerrogativa a obtenção de lucros.

É adequado considerar como hipótese de incidência do tributo o limite total da despesa realizada. No entanto, há cidadãos incapazes economicamente de arcar com 0 pagamento de tributos, os quais poderão obter isenção total de referido pagamento, vendo- 
se a eficácia jurídica e social do principio da capacidade contributiva operar (eficácia relativa complementável).

No caso de contribuintes que não preenchem os requisitos para obtenção de isenção e, ainda, não dispõem de capacidade econômica para efetuar o pagamento integral do tributo, o legislador ordinário deverá suprir a lacuna técnica e ontológia existente na legislação tributária, editando leis que permitam a adequação dos casos referidos, à real possibilidades dos cidadãos, realizando-se, desta forma, ainda que indiretamente, a eficácia do principio em tela, em conexão com o principio da personalização.

O denominado "concurso de obrigações fiscais" ou carga tributária produzida sobre sujeitos passivos de relação tributária, decorre de tributos separados, os quais acabam resultando numa carga fiscal global excessiva, que supera a capacidade econômica do contribuinte. Devem, por isso, ser considerados tais tributos inconstitucionais, em nome da adequação dos princípios constitucionais ao mundo dos fatos; o que consiste na ocorrência da eficácia social dos princípios constitucionais.

A questão eficacional referente às imunidades encontra eficácia plena, na maioria dos casos elencados no art. 150, VI do Texto pátrio, fazendo-se exceção apenas para a hipótese descrita na alínea "c" do citado dispositivo, em cuja situação se reconhece ser o princípio dotado de eficácia relativa complementável, pois que dependente de legislação subconstitucional a Ihe assegurar eficácia.

Uma norma terá eficácia social se as circunstâncias de sua atuação forem condizentes à realidade social e aos valores aí insertos. Havendo discrepância entre essas hipóteses, dificilmente a norma será obedecida, faltando-Ihe eficácia social.

\section{Conclusão}

Para que se verifique eficácia social do princípio da capacidade contributiva, apurase a realização dos efeitos almejados pelo constituinte, quando da consignação, em sede constitucional, dos princípios da isonomia, dignidade da pessoa humana, moralidade, legalidade e demais princípios constitucionais tributários específicos, preconizados, também, em proteção do contribuinte, pelo seu respeito e cumprimento, pelo poder público, quando da exação fiscal.

Procedendo a essa diligência analítica, constata-se que o princípio da capacidade 
contributiva é dotado de eficácia social. A dicção do artigo 145, parágrafo 10 da Constituição Federal, confere ao princípio ora em exame, o papel de norma cogente e não somente programática, conferindo ao legislador, ao intérprete e ao aplicador, o dever de observá-lo.

Os aplicadores e os estudiosos do Direito vêm, embalados pelo desenrolar histórico, a partir da promulgação da Constituição Federal de 1988, insistido, indevidamente, no questionamento da limitação, ou não, do princípio da capacidade contributiva aos impostos, dedicando estudos à apuração do sentido da expressão sempre que possível previsto no primeiro parágrafo, do art. 145, da Constituição, sem vislumbrarem a obrigatoriedade do respeito ao princípio em relação aos tributos em geral, independente de expressa previsão neste sentido em sede constitucional.

Isto porque a redação do citado dispositivo constitucional é falha, permitindo uma gama variada de interpretações, que acabam restringindo o espectro de ação do principio. 0 ideal seria que 0 atual texto tivesse se reportado ao preceito contido no artigo 202 da Constituição de 1946, de modo que o Poder Judiciário ficasse com a atribuição de desenhar os lineamentos do princípio, quando provocado pelo cidadão, ansioso na defesa de seus direitos.

Ocorre que, ao contrário dessa realidade, independentemente dos motivos que 0 justificam, o poder público vem, reiteradamente, respeitando o princípio em análise, em relação com os princípios genéricos e específicos que o norteiam, também, em proteção do cidadão, sempre que institui um tributo ou exige os já existentes. A realidade é que a administração pública vem efetivamente alcançando os efeitos que advém da aplicação do princípio da capacidade contributiva.

Tal assertiva deriva da análise individual dos tributos em geral, e não da análise conjunta. Porém, se fosse possível a análise da existência da eficácia social do princípio da capacidade contributiva a partir dos tributos existentes no país, todos somados, a conclusão seria outra. Isto porque a carga tributária que recai sobre o contribuinte no Brasil, atualmente das maiores do mundo, como público e notório, está longe da obediência e da finalidade do princípio.

Mas, como se analisa a questão particularizada de cada tributo, em conjunto com todos os princípios constitucionais que alicerçam o princípio em comento, verifica-se, como já afirmado, a eficácia social do princípio da capacidade contributiva, como forma de 
realizar-se a justiça fiscal e social, tão almejada.

\section{Referências}

ATALIBA, Geraldo. República e Constituição. São Paulo: RT, 1985.

ATALIBA, Geraldo. Sistema Constitucional Tributário Brasileiro. São Paulo: RT, 1968.

BALEEIRO, Aliomar. Limitações constitucionais ao poder de tributar. 7. ed. Rio de Janeiro: Forense, 1998.

BARCELLOS, Ana Paula de. A eficácia jurídica dos princípios constitucionais: o princípio da dignidade humana. Rio de Janeiro: Renovar, 2002.

BARRETO, Aires. Vedação ao efeito confisco. Revista de Direito Tributário, São Paulo, n. 64, p.96-106, 1993.

BASTOS, Celso Ribeiro. Interpretação e aplicabilidade das normas constitucionais. São Paulo: Saraiva, 1982.

BECKER, Alfredo Augusto. Teoria Geral do Direito Tributário. 2. ed. São Paulo: Saraiva, 1972. CANOTILHO, José J oaquim Gomes. Direito Constitucional e Teoria da Constituição. 5. ed. Coimbra: Almedina, 2002.

CARRAZZA, Roque Antonio. Curso de Direito Constitucional Tributário. São Paulo: RT, 1991.

CARVALHO, Paulo de Barros. Curso de Direito Tributário. São Paulo: Saraiva, 1986.

CARVALHO, Paulo de Barros. Teoria da norma tributária. 2. ed.. São Paulo, 1981.

CLÉVE, Clèmerson M erlin. A fiscalização abstrata da constitucionalidade no direito brasileiro. 2. ed. São Paulo: RT, 2000.

CÓDIGO TRIBUTÁRIO NACIONAL. Lei 5.172 de 25/10/1966.

COÊLHO, Sacha Calmon Navarro. Curso de Direito Tributário Brasileiro. 6. ed. Rio de Janeiro: Forense, 2001.

CONTI, José M aurício. Princípios tributários da capacidade contributiva e da progressividade. São Paulo: Dialética, 1996.

CONSTITUIÇAO DA REPÚBUCA FEDERATIVA DO BRASIL: promulgada em 25 de outubro de 1988. 
COSTA, Regina Helena. Princípio da capacidade contributiva. 2. ed. São Paulo: Malheiros, 1996.

DINIZ, M aria Helena. Norma constitucional e seus efeitos. São Paulo: Saraiva, 2003.

FALCAO, Amílcar. Fato gerador da obrigação tributária. 4. ed. São Paulo: RT, 1977.

FANTOZZ, Augusto. Diritto Tributário. Torino: UTET, 1984. v.1.

GAFFURI, Franco. L'attitudine alla contribuzione. M ilano: Giuffrè, 1969.

GIARDINA, Emilio. Le basi teoriche del principio di capacita contributiva. M ilano: Giuffrè, 1961.

GRIZIOTTI, Benvenuto. Principii di Política, di Diritto e Scienza dalle Finanze. Padova:

CEDAM, 1929.

GRUPENM ACHER, Betina Treiger. Eficácia e aplicabilidade das limitações constitucionais ao poder de tributar. São Paulo: Resenha Tributária, 1997.

KELSEN, Hans. Teoria Pura do Direito. São Paulo: Martins Fontes, 1987, tradução de João Baptista machado, revisão para a edição brasileira Silvana Vieira, 2a edição brasileira junho de 1987.

M ACHADO, Hugo de Brito. Os princípios jurídicos da tributação na Constituição de 1988. 2. ed. Ver. e ampl. São Paulo: Ed. Revista dos Tribunais, 1989.

MAFFEZZONI, Federico. II princípio di capacita contributiva nel Diritto Finanziario. Torino: UTET, 1965.

MELLO, Celso Antônio Bandeira. Curso de Direito Administrativo. 11. ed. São Paulo: Saraiva, 1999.

RAWLS, John. Uma teoria da justiça. Tradução de Almiro Pisetta e Lenita M. R. Esteves. São Paulo: Martins Fontes, 1997.

SILVA, José Afonso. Aplicabilidade das normas constitucionais. São Paulo: RT, 1968.

UCKM AR, Victor. Principii comuni di Diritto Costituzionale Tributário. Padova: CEDAM , 1959. 